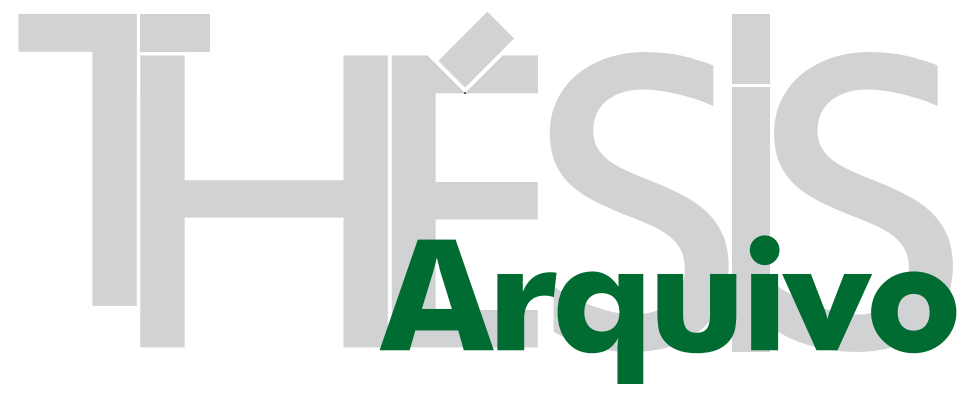




\title{
A MATEMÁTICA DA VILLA IDEAL Colin Rowe
}

Tradução Aurora Neiva Revisão Rachel Coutinho

\begin{abstract}
Há duas causas da beleza: uma natural e outra costumeira. A natural vem da geometria e consiste na uniformidade, ou seja, na igualdade e proporção. A beleza costumeira é gerada pelo uso, já que a familiaridade faz crescer um amor por algo que, em si, não é necessariamente belo. Aqui reside a grande origem dos erros, mas sempre o verdadeiro teste é a beleza natural ou geométrica. As figuras geométricas são naturalmente mais belas do que as irregulares; o quadrado e o círculo são as mais bonitas; em seguida vêm o paralelogramo e o oval. Há apenas duas posições belas de linhas retas, a perpendicular e a horizontal; isso vem da Natureza e, por conseguinte, da necessidade, tal como o ereto da firmeza.
\end{abstract}

1 NE: Todas as imagens reproduzidas aqui são páginas da edição publicada em 1978 pelo The MIT Press.

2 Isaac Ware, ed. e trad., The Four Books of Palladio's Architecture, Londres, 1738, p. 41.
Sir Christopher Wren, Parentalia

C

Como tipo ideal de edificação centralizada, a Villa Capra-Rotonda de Palladio (Figura 1) ${ }^{1}$, talvez mais do que qualquer outra, impõe-se na imaginação. Matemática, abstrata, quadrangular, sem função aparente e memorável, as residências dela derivadas tiveram distribuição universal; e Palladio, quando escreve sobre ela, é lírico.

O local é o que há de mais agradável e encantador, porque fica em uma pequena colina de acesso muito fácil; é banhado, de um lado, pelo Bacchiglione, um rio navegável, e do outro, é cercado de elevações as mais acolhedoras que parecem um enorme teatro, todas plantadas com excelentes árvores frutíferas e videiras das mais delicadas; e, portanto, como de qualquer parte se disfruta das mais belas vistas, algumas limitadas, outras mais amplas, e outras que alcançam o horizonte, formam-se pórticos naturais por todos os lados. ${ }^{2}$ 

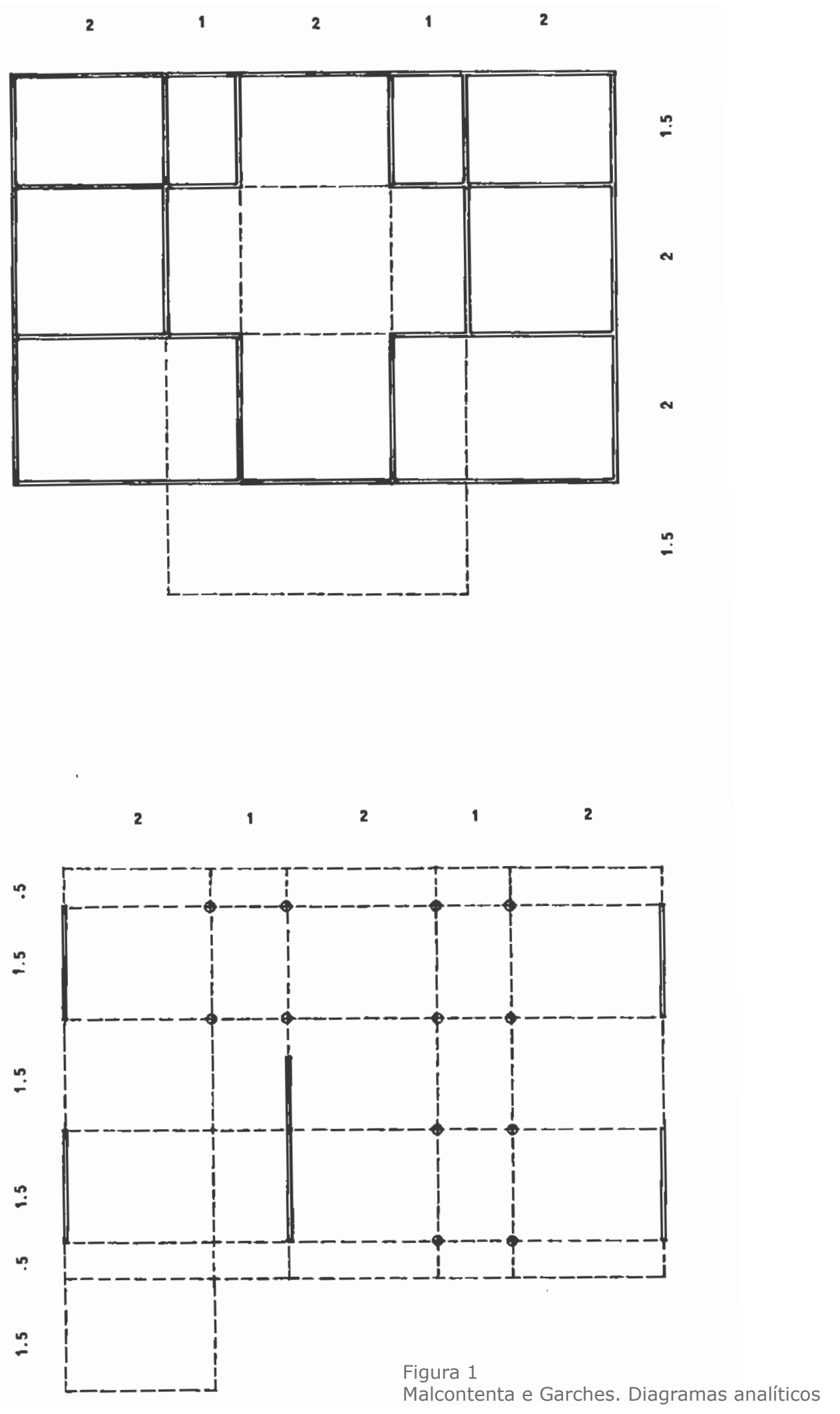

Quando a mente se prepara para um por meio de outro, não há como não se recordar de uma passagem de Precisões de Le Corbusier. Não menos lírico, porém um tanto mais explosivo, Le Corbusier descreve o sítio da Villa Savoye em Poissy. (Figura 2). 


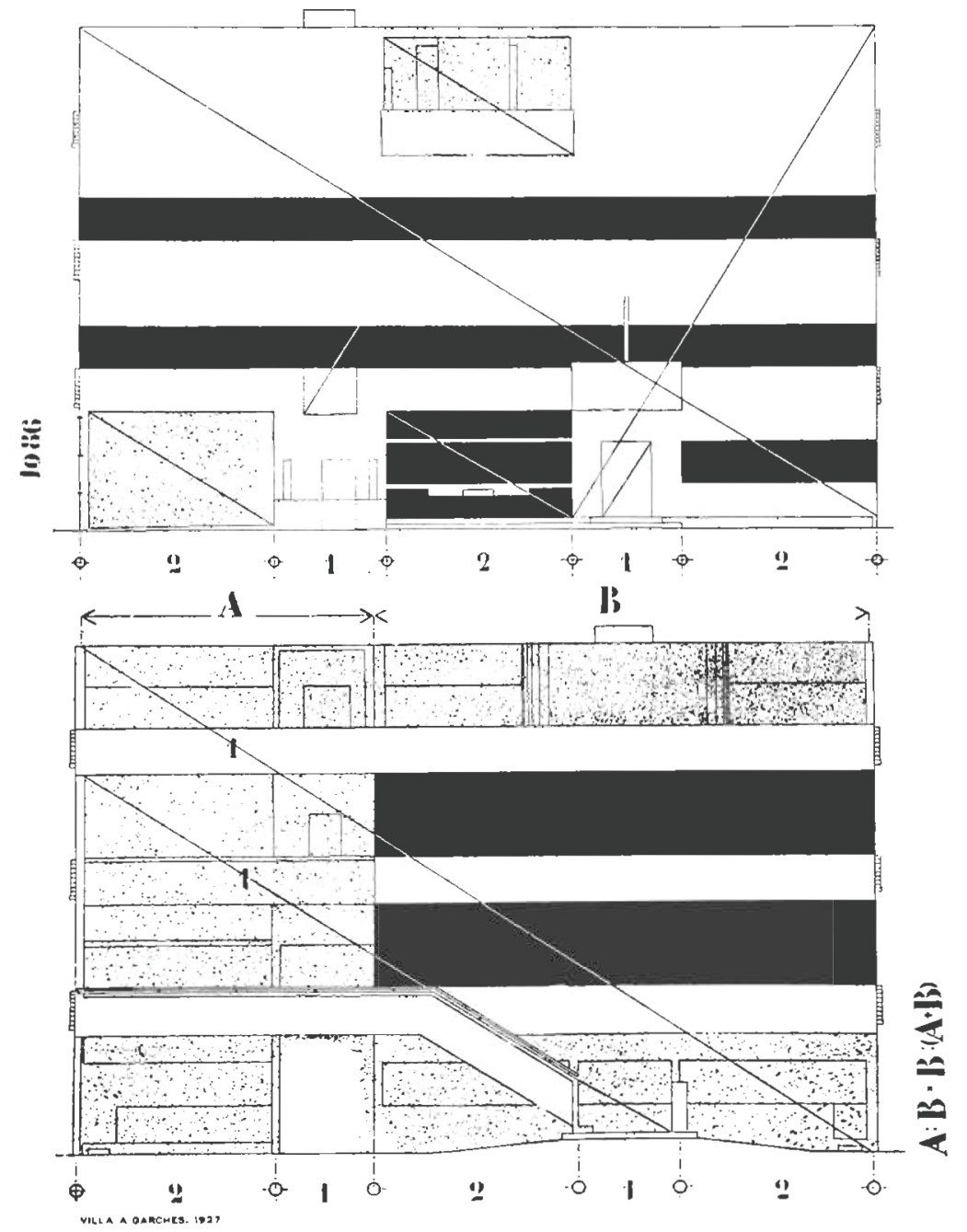

Figura 2

Garches, elevações

3 NT: esta citação foi retirada da tradução brasileira: Precisões: sobre um estado presente da arquitetura e urbanismo / Le Corbusier; tradução Carlos Eugênio Marcondes de Moura São Paulo: Cosac \& Naify, 2004, p. 138-142.
O local: um gramado vasto e encurvado. [...] A casa é uma caixa no ar [...] no meio dos prados, dominando o pomar. [...] A planta é pura. [...]. Sua situação é a mais correta possível, na paisagem agreste de Poissy [...]. Os moradores foram morar lá porque esse campo agreste era belo como a vida que ele oferecia. Mantido intacto, eles o contemplarão do alto de seus jardins suspensos ou das quatro faces de suas janelas corridas. Sua vida doméstica se inserirá em um sonho virgiliano. 3

A Villa Savoye tem sido objeto de um sem-número de interpretações. Realmente pode ser considerada uma 'máquina de morar', um arranjo de volumes e espaços que se interpenetram, uma emanação do tempo-espaço; mas a referência sugestiva aos sonhos de Virgílio pode nos fazer pensar na descrição da Rotonda feita por Palladio. A paisagem de Palladio é mais agrária 
e bucólica, faz menos evocações a cenários pastoris indomados e é de escala maior; mas o efeito das duas passagens é, por assim dizer, o mesmo.

Palladio, em outro texto, amplifica a vida ideal de uma villa. O proprietário, a partir do interior de um fragmento de uma ordem criada, assistirá à maturação de suas posses e saboreará a sensação picante do contraste entre seus campos e jardins; enquanto estiver refletindo sobre a mutabilidade, contemplará, ao longo dos anos, as antigas virtudes de uma humanidade mais simples e o ordenamento harmonioso de sua vida e seu patrimônio se tornará uma analogia do paraíso.

Era comum os sábios da antiguidade se recolherem em de-
terminados lugares, onde, contando com a frequente visita
de amigos e parentes virtuosos, e com casas, jardins, fon-
tes e locais agradáveis como esses, e acima de tudo com as
suas próprias virtudes, facilmente conseguiam alcançar o
máximo de felicidade possível aqui na terra. ${ }^{4}$

Talvez esses fossem os sonhos de Virgílio; e, interpretados livremente, com o passar do tempo, tais sonhos absorveram todas as noções de virtude, excelência, esplendor imperial e decadência romanas que constituem a reconstrução imaginária do mundo antigo. Teria sido, provavelmente, nas paisagens das pinturas de Poussin - com suas aparições portentosas da antiguidade - que Palladio teria se sentido em casa; talvez os fundamentos dessa paisagem, o contraste pungente entre o cubo desconectado e seu cenário na paisagem agreste, entre o volume geométrico e a aparência de uma natureza sem deficiências, estivessem por trás da alusão de Le Corbusier a Roma. Se a arquitetura na Rotonda forma o cenário da vida prazerosa, em Poissy ela é, certamente, o pano de fundo para uma vida eficiente do ponto de vista lírico; e, se a vida rural contemporânea ainda não é sancionada pelo uso convencional, aparentemente a nostalgia virgiliana continua presente. A partir dos cômodos higienicamente equipados, pausando enquanto o visitante sobe as rampas, sem dúvida alguma, a memória evocada do poema Geórgicas ${ }^{5}$ se interpõe, e, talvez, essa referência histórica se torne um estímulo à medida que o carro do visitante vai saindo em direção a Paris.

No entanto, uma comparação mais específica que se pode fazer é entre a Villa Foscari de Palladio, a Malcontenta, construída por volta de $1550-60$ (Figuras 3 e 4), e a residência que em 1927 Le Corbusier projetou para o Sr. e a Sra. Michael Stein em Garches (Figuras 5 e 6 ).
${ }^{4}$ Ware, p. 46.

5 NT: aqui Rowe faz referência à obra Geórgicas de Virgílio em que o poeta apresenta uma visão bucólica da vida no campo. 

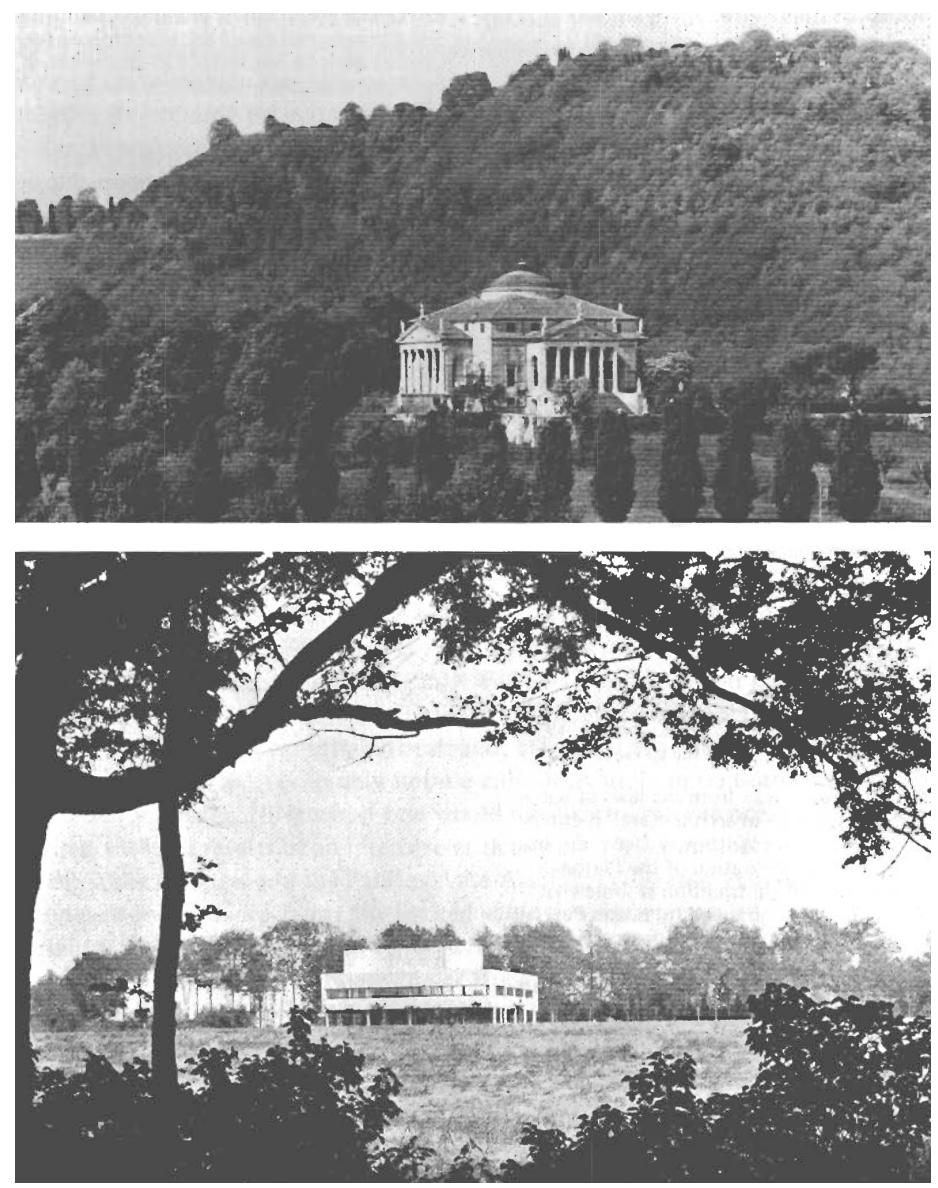

Figuras 3 e 4

Villa Capra-Rotonda, Vicenza. Andrea Palladio, c. 1550; Villa Savoye, Poissy. Le Corbusier, 1929-31

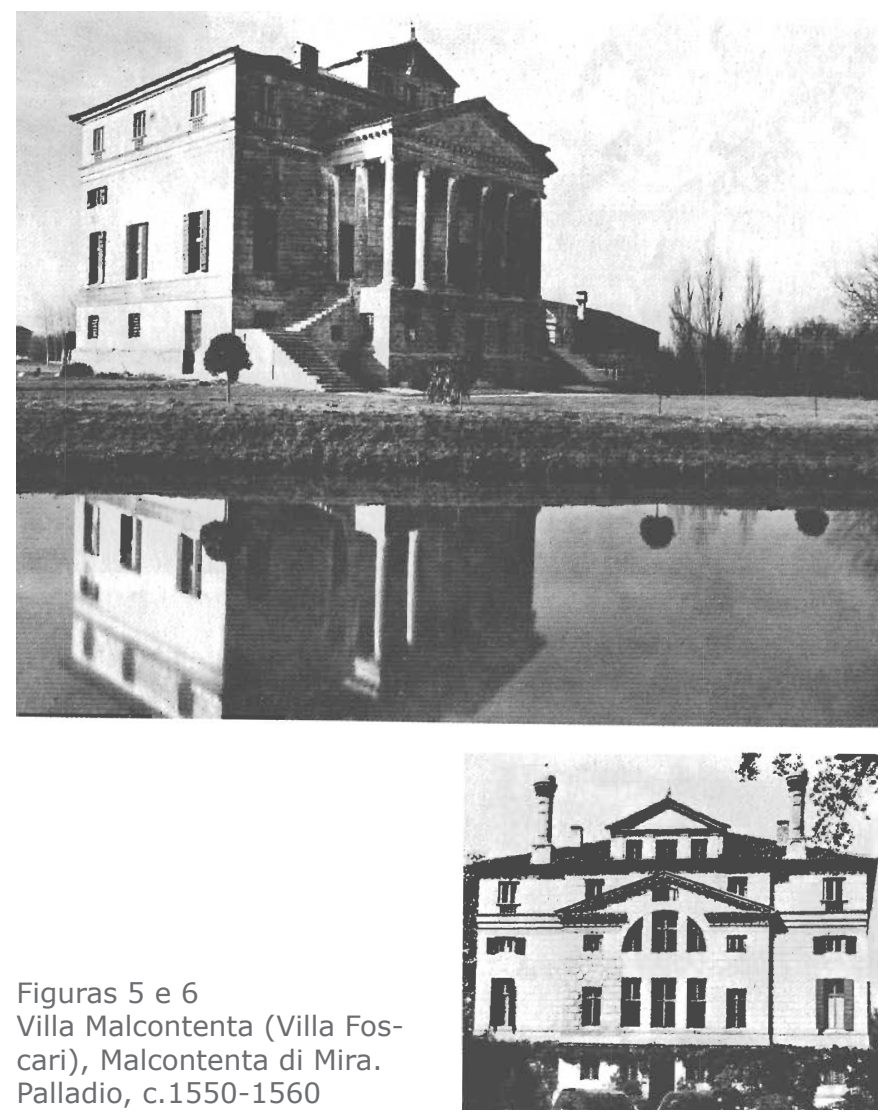


Essas duas edificações, em termos de formas e evocações, são, superficialmente, tão distintas no todo que aproximá-las poderia parecer uma brincadeira; mas, se a obsessiva gravidade psicológica e física da Malcontenta não tem paralelo com uma casa que às vezes deseja ser um navio, outras um ginásio, tal diferença de temperamento não deveria impedir que se faça uma análise minuciosa.

Pois, no primeiro caso, tanto Garches como Malcontenta são concebidas como blocos únicos (Figuras 7 e 8); e levando-se em consideração as variações de tratamento dos telhados, pode-se notar que ambas são blocos com volumes correspondentes, cada um medindo 8 unidades de comprimento, por $5 \frac{1}{2}$ de largura, e 5 de altura. Além disso, há uma estrutura em projeção equiparável a ser observada. Cada residência exibe (e esconde) um ritmo alternativo de intervalos espaciais duplos e únicos; e cada uma, lendo-se da frente para trás, exibe uma distribuição equivalente tripartite de linhas de apoio (Figura 1 ).
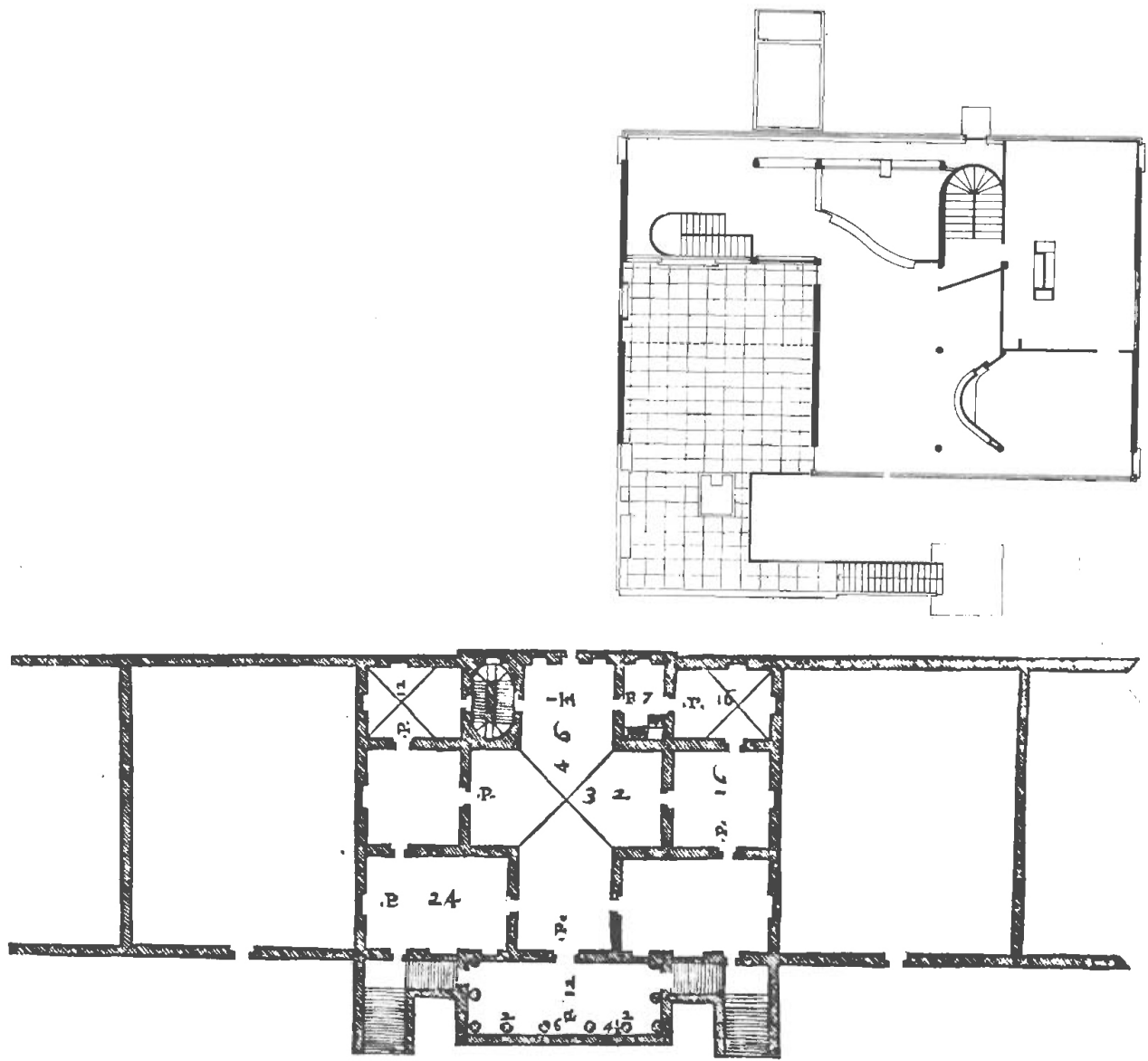
Mas, nesse estágio, talvez seja melhor relativizar a comparação. Porque, se a distribuição das coordenadas horizontais básicas é, em ambos os casos, praticamente a mesma, ainda há algumas diferenças leves e significativas relativas à distribuição dessas linhas de apoio que ficam paralelas às fachadas; e assim, em Garches, lendo-se da parte anterior para a posterior, o intervalo espacial básico prossegue na proporção de $1 / 2: 1 \frac{1}{2}: 1 \frac{11 / 2}{2} 1 \frac{112}{2}: 1 \frac{1}{2}$, ao passo que em Malcontenta somos apresentados à sequência $2: 2: 1 \frac{11}{2}$. Em outras palavras, através do uso de uma meia unidade em balanço, Le Corbusier obtém uma compressão para o elemento central em projeção, transferindo, assim, a atenção do observador para outro lugar enquanto Palladio assegura uma posição dominante à divisão central, com uma progressão em direção ao pórtico, o qual conduz o foco de atenção totalmente para essas duas áreas. Um dos esquemas é, portanto, potencialmente disperso e possivelmente igualitário e o outro, concêntrico e certamente hierárquico; mas, atentando-se para tal diferença, pode-se simplesmente acrescentar que, em ambos os casos, um elemento em projeção - um terraço saliente ou um pórtico anexado - ocupa $1 \frac{1}{2} 2$ unidade de profundidade.

É claro que as estruturas não são para serem comparadas; e, até certo ponto, ambos os arquitetos veem a estrutura como uma justificativa para seus propósitos. Assim sendo, Palladio utiliza uma parede estrutural sólida; e sobre esse sistema ele escreve:

\begin{abstract}
Deve ser observado que aqueles compartimentos à direita correspondem aos da esquerda, que então o material pode ser o mesmo nos dois lugares, e que as paredes podem suportar igualmente a carga do telhado; porque se as paredes forem maiores em uma parte e menores na outra, a segunda será mais firme para aguentar o peso, por ficar mais próxima das paredes, e a primeira mais fraca, o que causará, com o tempo, grandes inconveniências e acabará por arruinar toda a obra. ${ }^{6}$
\end{abstract}

6 Ware, p. 27.

Palladio está preocupado com a disposição lógica dos motivos aceitos como dogma, mas tenta descobrir uma razão estrutural para o seu planejamento das simetrias; por outro lado, Le Corbusier, que está apresentando provas de que a estrutura é a base para os elementos formais do projeto, contrasta o novo sistema com o antigo e é um pouco mais abrangente.

Relembro o "plano paralisado" da casa de pedra e o plano a que chegamos, com a casa de ferro ou de concreto armado:

planta livre fachada livre esqueleto independente janelas corridas ou pano de vidro 
pilotis

teto-jardim

e o interior provido de 'escaninhos' e livre de acumulação de móveis. ${ }^{7}$

O sistema estrutural de Palladio torna quase que necessário repetir o mesmo plano em cada nível da edificação, enquanto que o apoio pontual permite que Le Corbusier faça um arranjo flexível; mas ambos os arquitetos fazem uma alegação que vai muito além das razões que apresentam. Estruturas de paredes sólidas, declara Palladio, demandam simetria absoluta; uma edificação de estrutura armada, anuncia Le Corbusier, requer um arranjo livre: mas essas devem ser, ao menos parcialmente, exigências pessoais do alto estilo pois construções assimétricas de estrutura tradicional continuam de pé e até as de estrutura armada de projetos convencionais continuam satisfatórias.

Em ambas as residências há um piano nobile subindose um piso, que se liga ao jardim através de um terraço ou pórtico, e um lance (ou lances) de escada. $\mathrm{Na}$ Malcontenta, o andar principal apresenta um hall em forma de cruz com duas suítes de três cômodos cada, simetricamente dispostas em relação ao hall, e duas escadarias; mas em Garches não há nada que possa ser descrito tão de imediato. Em Garches há um hall central e duas escadarias; mas enquanto uma delas ocupa uma posição semelhante às de Malcontenta, a outra foi girada a noventa graus. Além disso, o hall de entrada é revelado a partir desse nível por um vã assimétrico aberto no piso; e o terraço (que corresponde ao pórtico de Malcontenta) torna-se parcialmente um volume reentrante que impede a visão de uma linha de apoio, disposto em relação ao cômodo principal de forma claramente menos perceptível. Assim, em Garches, o formato em cruz sobrevive apenas como um vestígio (talvez se possa considerar que seja indicado pela ábside da sala de jantar?); e portanto, em vez da centralidade do espaço maior de Palladio, Corbusier alcança o equilíbrio da forma em $Z$ com o auxílio da inserção da pequena biblioteca no apartamento principal. Finalmente, enquanto em Malcontenta existe um eixo em cruz muito evidente, em Garches tal movimento transversal, sugerido pelos espaços vazios centrais das paredes ao fundo, só pode se desenvolver de maneira implícita e fragmentária.

A parede em Malcontenta é composta de um elemento sólido tradicional trespassado por aberturas verticais com ênfase central no pórtico e destaque subsidiário nas janelas externas colocadas na direção das extremidades da fachada. A baia dupla no centro da edificação que sustenta os frontões superiores do telhado
7 NT: Esta citação foi retirada da tradução brasileira de Carlos Eugênio Marcondes do livro Precisões de Le Corbusier, p. 127. 
é expressa em uma das frentes por uma única porta, e na outra por um adorno representando "banhos romanos"; e, horizontalmente, a parede também possui três divisões primárias: base; piano nobile, correspondendo à ordem jônica do pórtico; e sótão sobreposto. A base funciona como um apoio sólido saliente sobre o qual repousa a casa; mas, enquanto o piano nobile e o sótão são rusticados, a base é tratada como uma superfície plana e a sensação de que ali se carrega um grande peso é alcançada através dessa inversão altamente emotiva da ordem usual.

Novamente a situação em Garches é mais complexa; e lá a exploração do sistema estrutural leva a uma concepção de parede como uma série de faixas horizontais - uma estratégia que coloca relevância equivalente no centro e na extremidade da fachada e que é então mantida na tendência de Le Corbusier de suprimir o alongamento dos dois balcões. Através de tais recursos qualquer sistema de destaque de axialidade vertical e de inflexão de parede que a isso conduza é profundamente modificado; e o resultado imediato na elevação do jardim de Garches se revela no deslocamento dos elementos que podem ser considerados equivalentes ao pórtico e frontão sobreposto de Malcontenta. Esses elementos se tornam separados; e transpostos como pavilhão de terraço e telhado, um ocupa os dois (ou três) balcões à esquerda da fachada, e o outro uma posição central no elemento sólido e um assimétrico em toda a fachada.

Por outro lado, entrada em Garches retém o que pode ser considerado como o análogo ao frontão de Palladio. Esse é o elemento central do andar superior; mas então nota-se também, apesar de sua posição simétrica, que o desenvolvimento desse elemento dentro de si próprio não é simétrico. Além disso não promove a simetria na fachada como um todo; e, embora tenha uma resposta na grande janela central do hall de entrada, visto que os cortes horizontais das janelas agem para proibir qualquer ligação explícita com essas duas manifestações, segue-se na elevação algo muito semelhante àquela afirmação e negação simultâneas de centralidade que é exibida na planta. Assim se estipula um foco central; seu desenvolvimento é inibido; e então ocorre um deslocamento e rompimento de exatamente o que Palladio teria suposto ser uma ênfase normativa.

Outro ponto importante de diferença encontra-se na interpretação do telhado. Em Malcontenta ele forma uma superestrutura piramidal que amplia o volume da casa (Figura 9), enquanto em Garches o telhado 
se constitui de uma superfície plana, que serve de piso para um compartimento recortado do volume da casa, causando a sua diminuição. Portanto, em uma das residências o comportamento do telhado pode ser descrito como aditivo e na outra, subtrativo; mas, excetuando-se essa importante distinção, ambos os telhados têm como acabamento uma variedade de incidentes, regulares ou aleatórios, frontões ou paviIhões, os quais, na mesma medida, se relacionam de maneira importante com as superfícies verticais das paredes abaixo.

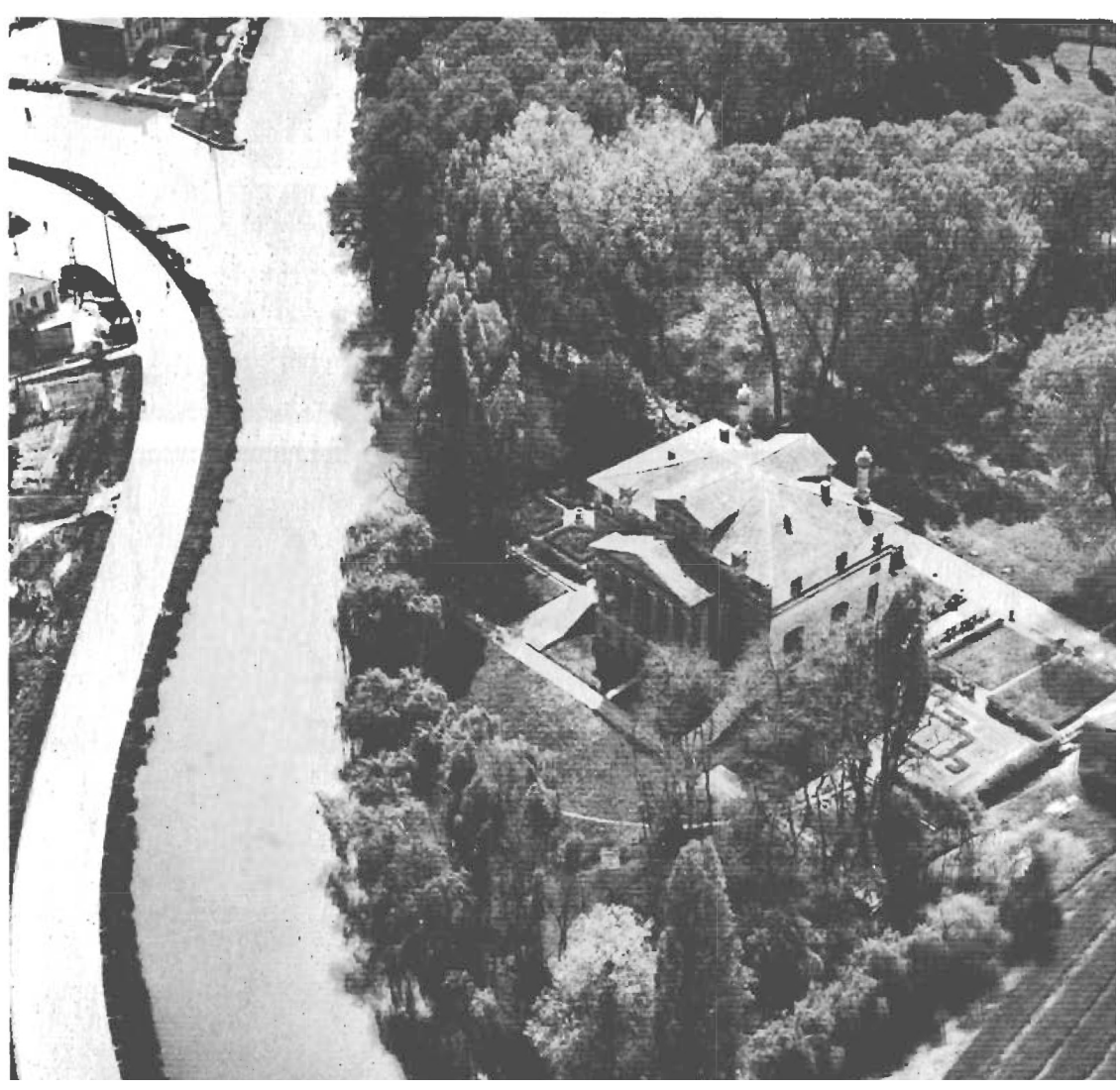

Figura 9

Villa Stein, Garches. Le Corbusier, 1927

Era o senso comum vigente nos círculos onde atuava Palladio que a matemática e a concordância musical fundamentavam a proporção ideal. Ali sentia-se que havia uma correspondência entre os números perfeitos, as proporções da figura humana e os elementos da harmonia musical; 8 e Sir Henry Wotton, na qualidade de embaixador britânico em Veneza, numa ocasião posterior, reflete parcialmente tal atitude quando

8 Devo essas observações específicas a Rudolf Wittkower, Architectural Principles in the Age of Humaescreve:

Os dois principais intervalos consonantes que mais arrebatam o ouvido são, por razões intrínsecas à natureza, a quinta justa e a oitava justa, da qual a primeira se origina radicalmente da proporção entre dois e três. A outra, do 
9 Sir Henry Wotton, The Elements of Architecture, publicado em John Evelyn, Parallel of the Ancient Architecture with the Modern, 3a ed., Londres, 1723, p. xv.

10 Giacomo Leoni, Ten Books on Modern Architecture by Leon Battista Alberti, 3a. ed., Londres, 1755, p. 196.

11 NT: no texto em inglês, o autor não traduz as citações de Le Corbusier. Em português, os trechos citados leem-se da seguinte maneira: "verdades reconfortantes" e "não se sai de sua obra sem se ter a certeza de que se chegou à coisa exata". Le Corbusier e Pierre Jeanneret, Oeuvre complete 1910-1929, 3a. ed, Zurique, 1943, p. 144. Como explica Rowe em nota de rodapé, tais comentários dizem respeito a Garches.

12 "O rompimento da arquitetura com as leis de proporção harmônica" é discutido extensamente em Wittower (ver notas 7 e 8), mas a desintegração paralela da tradição crítica platônico-aristotélica é observada de uma maneira um tanto o quanto lacônica por Logan Pearsall Smith: "Há grandes jovens também cujas realizações se pode invejar; - garoto David que matou Golias e o Bispo Berkeley que aniquilou, aos vinte e cinco anos de idade, em 1710, o mundo externo com seu livro in-octavo; e o jovem David Hume, que, em 1739, ao varrer todos os adereços da compreensão humana, destruiu para todo o sempre toda a possibilidade do conhecimento", Logan Pearsall Smith, All Trivia, Londres, 1947, p. 159. intervalo duplo, entre um e dois, ou entre dois e quatro, etc. Agora, se transportarmos tais proporções de objetos audíveis para os visíveis, e as aplicarmos como acharmos mais adequado, sem dúvida alguma resultará, de qualquer uma delas , uma satisfação para os olhos repleta de graça e harmonia. 9

Na realidade, não se sugeriu que as proporções arquitetônicas se derivassem das harmonias musicais, mas, ao invés disso, que as leis de proporção tivessem sido estabelecidas segundo princípios matemáticos e difundidas amplamente. O universo de especulação platônico e pitagoreano compunha-se de relações numéricas mais simples, formado dentro de um triângulo obtido pelo quadrado e o cubo dos números 1,2 , 3. Além disso, suas qualidades, ritmos e relações se estabeleciam dentro desse quadro de números chegando até 27; e se tais números governavam os trabalhos de Deus, considerava-se apropriado que os do ser humano deveriam ser construídos de maneira semelhante, que um prédio deveria ser representante, em termos microcósmicos, do processo exibido, em escala maior, nos mecanismos de funcionamento do mundo. Nas palavras de Alberti: "A natureza de certo age com consistência e constante analogia em todas as suas operações", ${ }^{10}$ e, portanto, o que é patente na música deve também ser na arquitetura. Assim, com a proporção como uma projeção da harmonia do universo, sua base - tanto científica como religiosa - era quase invulnerável; e um Palladio poderia desfrutar as satisfações de uma estética considerada totalmente objetiva.

Le Corbusier expressou convicções semelhantes sobre proporção. A matemática traz "des vérités reconfortantes" e "on ne quitte pas son ouvrage qu'avec la certitude d'être arrivé à la chose exacte"11, mas se é, de fato, a exatidão o que Le Corbusier busca, em suas construções não é a clareza inquestionável dos volumes de Palladio que se encontra. Em vez disso, constata-se um tipo de obscuridade planejada; e, consequentemente, enquanto em Malcontenta a geometria é difundida pelos volumes internos de toda a construção, em Garches parece que ela reside apenas no bloco como um todo e na disposição de seus suportes.

A postura teórica sobre a qual se sustentava a posição de Palladio foi desarticulada no século XVIII quando a proporção se tornou uma questão de sensibilidade individual e inspiração pessoal ${ }^{12}$; e Le Corbusier, apesar de toda a comodidade que a matemática Ihe oferecia, simplesmente em termos de sua localização na história não pode ocupar tal posição inatacável. O funcionalismo foi, talvez, uma tentativa altamen- 
te positivista de reafirmar uma estética científica que pudesse possuir o valor objetivo de antigamente, e a crítica platônico-aristotélica definitiva. Mas tal interpretação carecia de refinamento. Os resultados podem ser mensurados em termos de processo e as proporções são aparentemente acidentais e gratuitas; e é em contradição a essa teoria que Le Corbusier impõe padrões matemáticos a suas construções. Essas são as tais "vérités reconfortantes", ou seja, as verdades reconfortantes.

Assim, ou em razão ou apesar da teoria ambos os arquitetos compartilham de um padrão comum, o matemático, definido por Wren como beleza "natural"; e, dentro das limitações de um programa específico, não é de se surpreender, portanto, que os dois blocos tenham volumes correspondentes ou que ambos os arquitetos tenham escolhido anunciar, de maneira didática, a adoção de fórmulas matemáticas. Dos dois - e, talvez, de maneira bem característica - Le Corbusier é o mais agressivo; e em Garches ele indica, criteriosamente, as relações de que se vale por meio de um aparato de linhas reguladoras e figuras e da inserção nos desenhos de elevações da proporção áurea, $A$ : B $=B:(A+B)$ (Figura 2).

Mas, se as fachadas de Le Corbusier são para ele demonstrações primordiais das virtudes da disciplina da matemática, com Palladio parece que a prova cabal de sua teoria se encontra na própria planta. Ao longo de sua obra Quattro libri, ${ }^{13}$ Palladio equipa sistematicamente tanto as plantas como as elevações com suas apologéticas numéricas (Figura 8); mas as pequenas cifras crípticas que ele anexa aos desenhos sempre parecem ser mais convincentes, ou, pelo menos, mais claras, quando as relaciona à planta. $E$, possivelmente, tal fato seja compreensível, pois, em uma residência como a Malcontenta, a planta pode ser visto como uma demonstração da beleza "natural", como algo puro, abstrato e sem complicações; mas as fachadas são, por necessidade, adulteradas (embora raramente causando prejuízo) através da utilização intrusiva de material "costumeiro". As fachadas se tornam complicadas; sua lógica platônica estrita pode ser viciada, em última análise, pela presença tradicional, neste caso, da ordem jônica, que possui uma lógica própria e que, inevitavelmente, introduz um sistema alternativo de medição (Figuras 10 e 11).

Pode-se supor que o conflito entre as exigências "costumeiras" da ordem e uma série de relações "naturais" seja a fonte da qual as fachadas de Malcontenta se derivam. São sugestivas, evocativas, mas não
13 NT: Título original da obra de Palladio já citada. 
são suscetíveis, facilmente ou em sua totalidade, à regulação matemática; e, portanto, é, novamente, à planta de Palladio que se deve retornar. Acompanhadas de dimensões explanatórias, as duas suítes que abrangem três cômodos cada podem ser lidas, cada uma delas, como uma progressão de $3: 4$ para uma relação de 2 : 3 . Elas recebem a numeração $12: 16$, $16: 16$ e $16: 24$.
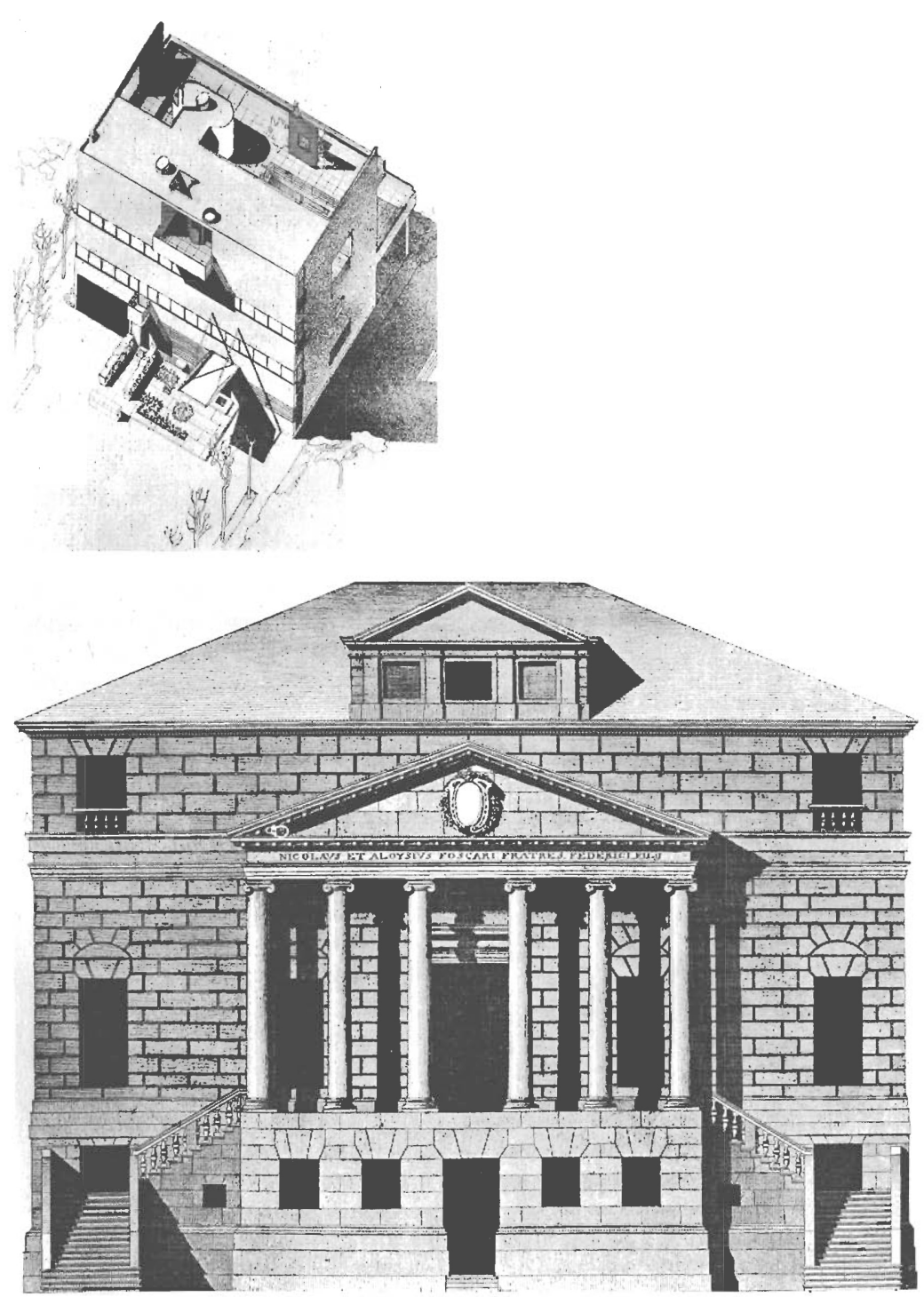

Figuras 10 e 11

Villa Malcontenta (Villa Foscari), Malcontenta di Mira. Palladio, c.1550-1560

14 Para as medidas internas reais e não ideais da Malcontenta, ver Ottavio Bertotti Scamozzi, Les batiments et les desseins de Andre Palladio, Vicenza, 1776-83

E aqui, da parte de Le Corbusier e Palladio, devemos reconhecer, se não duplicidade, pelo menos apenas um mero desejo; mas, se a razão de $3: 5=5: 8$ é apenas uma aproximação à proporção áurea, e se a medida ideal dos cômodos de Palladio não coincide com o tamanho verdadeiro, ${ }^{14}$ isso é de se esperar e não há vantagem alguma em se ir mais a fundo em 
tais inconsistências. Ao invés disso, seria muito mais oportuno examinar a preferência de Palladino pela divisão tripartida e a tendência de Le Corbusier de fazer a divisão em quatro partes.

Na Malcontenta, como já observado, as fachadas se dividem verticalmente em três áreas principais, a do pórtico e as das paredes em cada lado, e na horizontal prevalece a mesma situação, seguindo a sequência porão, piano nobile e sótão; mas em Garches, apesar do partido estrutural equivalente, é sempre a situação se não de uma, de pelo menos duas ou, alternadamente, de quatro áreas de interesse às quais somos apresentados. Assim, na elevação de entrada, é a questão de quatro e um que prevalece; e na fachada do jardim, essa partição se torna uma questão de quatro e dois.

Mas, em ambas as residências, há formulações detaIhadas do esquema dominante que se torna complicado devido à sua interação com um sistema subsidiário. Ou seja: é por meio de extensão vertical em arco e abóboda, diagonal da linha do telhado e frontão que Palladio modifica as asperezas geométricas de seu cubo; e tal uso dos elementos circulares e piramidais com o quadrado parece não só esconder mas também amplificar a severidade intrínseca dos volumes. Entretanto, o arco, a abóboda, e a pirâmide estão entre as prerrogativas da construção de parede sólida. Estão entre as liberdades da planta tradicional, o "plan paralysé"15; e a introdução de formas arqueadas e telhados de duas águas é uma liberdade que em Garches Le Corbusier é incapaz de se permitir. Pois na construção de estrutura armada obviamente não são, como na estrutura de parede sólida, os planos verticais que predominam. Pelo contrário, isso ocorre nos planos horizontais de lajes de piso e de cobertura (Figuras 12 e 13); e, portanto, a qualidade de paralisia que Le Corbusier observa na planta de estrutura de parede sólida é, até um certo ponto, transferida na construção em estrutura armada para a seção. A perfuração dos pisos, para dar um certo movimento vertical de espaço, é possível; mas a qualidade escultural de entalhe da construção desaparece e não pode haver nada que remeta à firmeza da transmutação seccional e da modulagem de volume próprias de Palladio. Em vez disso, seguindo os planos predominantes das lajes, na construção em estrutura armada a extensão e a elaboração devem ocorrer horizontalmente. Em outras palavras, a planta livre é trocado pela seção livre; mas as limitações do novo sistema são tão rigorosas quanto aquelas de antigamente; e, como se a estrutura de parede sólida tivesse virado de lado, com 15 Termo de Le Corbusier mantido
em francês no original de Rowe. 
as anteriores complexidades de seção e as sutilezas da elevação agora transpostas para a planta, pode haver aqui alguma razão para a opção pela planta por Palladio e a escolha de Le Corbusier pelas elevações como documentos, em cada caso, mais ilustrativos da norma matemática elementar.

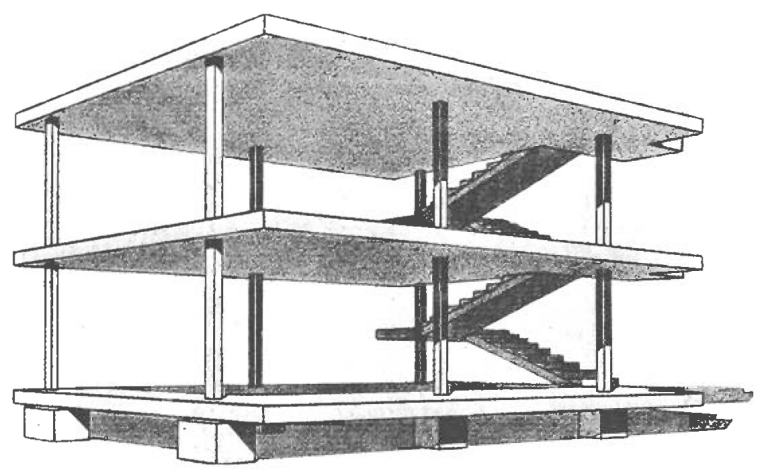

Figura 12

Villa Stein, Garches. Le Corbusier, 1927

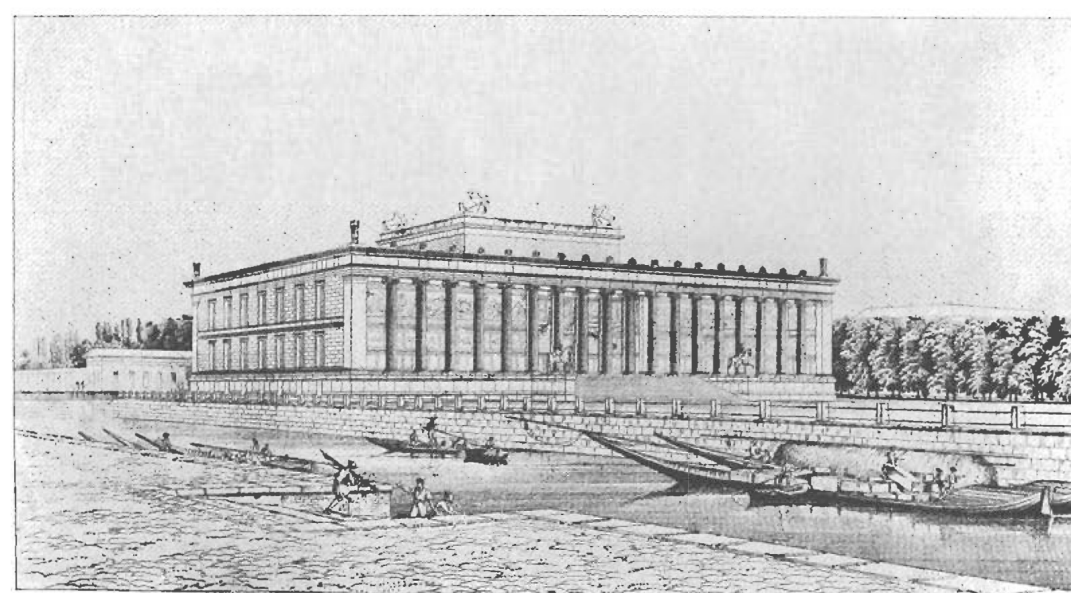

Figura 13

Villa Malcontenta (Villa Foscari), Malcontenta di Mira. Palladio, c.1550-1560

As ousadias espaciais do projeto de Garches continuam causar entusiasmo; mas pode por vezes parecer ser um interior que é aceito exclusivamente pelo intelecto - um intelecto operando dentro do vácuo de um palco. Portanto, em Garches observa-se uma permanente tensão entre o organizado e o aparentemente fortuito. Do ponto de vista conceitual, tudo é claro; mas sensorialmente, tudo causa profunda perplexidade. Há afirmações de um ideal hierárquico; há declarações opostas de um ideal igualitário. Ambas as 
mansões podem parecer apreensíveis por fora; mas por dentro, no salão cruciforme da Malcontenta, há uma pista para toda a construção enquanto em Garches nunca é possível obter, de nenhum ponto, uma impressão do todo. Pois na mansão de Le Corbusier a equidistância necessária entre piso e teto transmite a noção de que, entre os dois, todas as partes do volume são de igual importância; e, portanto, o desenvolvimento de um foco absoluto se torna algo arbitrário quando não impossível. Esse é o dilema apresentado pelo sistema; e Le Corbusier a ele responde. Aceita o princípio da extensão horizontal; assim, em Garches, o foco central é consistentemente rompido, a concentração em um determinado ponto se desintegra, e os fragmentos desmembrados do centro se tornam uma dispersão periférica incidental, uma instalação de interesse serial ao redor das extremidades da planta.

Mas é agora que tal sistema de extensão horizontal, lógico do ponto de vista conceitual, se coloca contra a fronteira rígida do bloco que, quase certamente, é sentido como um requisito perceptual; ${ }^{16} \mathrm{e}$, consequentemente, com a extensão horizontal verificada, Le Corbusier se vê obrigado a empregar um recurso oposto. Ou seja, ao cavar grandes volumes no bloco para formar um terraço e um telhado-jardim, ele introduz um impulso contrário de energia; e ao contrapor um momento explosivo a um implosivo, através da introdução de gestos invertidos paralelamente aos expansivos, mais uma vez o arquiteto faz uso simultâneo de estratégias conflitantes.

Através de tais complexidades, o sistema resultante (ou a simbiose de sistemas) coloca em plena evidência a subestrutura elementar e geométrica da construção; e, como sequência, o incidente periférico que se coloca no lugar do foco palladiano também pode ser acrescido de inversões (de terraço e de telhadojardim) que representam um desenvolvimento essencialmente análogo à estratégia de Palladio de extensão vertical.

Por fim, um processo equivalente a esse que ocorre na planta também se vê nas elevações, onde há a mesma difusão regular de valores e desenvolvimento irregular de pontos de concentração; e aqui, com as janelas horizontais transmitindo uma igualdade ao centro e às bordas das fachadas, uma desintegração de foco, que nunca é completa, causa uma rápida oscilação de atenção. Aqui, como no planta, não há nada residual, nada passivo, nada com movimento lento; e as extremidades do bloco, por tal razão, adquirem claridade e tensão intensas, como se estivessem tentan-
16 É possível supor que as fronteiras rígidas de Garches devessem ser consideradas necessárias do ponto de vista perceptual. A mansão é apresentada como uma de "quatro composições" em Oeuvre complete 1910-1929, p. 189; e, em Precisões, p. 83, Le Corbusier escreve sobre Garches: "Para se impor à atenção, para ocupar vigorosamente o espaço, seria necessário, antes de tudo, uma primeira superfície de forma perfeita, em seguida uma exaltação da platitude desta superfície, devida à contribuição de algumas saliências ou buracos que ocasionam um movimento direcionado para a frente e para trás". 
do impedir que o incidente periférico se desgarrasse por completo do bloco.

Uma comparação detalhada é menos fácil de se manter entre as duas mansões que, inicialmente, pareciam convidar uma correlação íntima: a mansão de Savoye e a Villa Rotonda e, possivelmente, isso se dá porque nenhuma das duas edificações é integralmente condensada na estrutura e no impacto emocional como são, respectivamente, a Garches anterior e a posterior Malcontenta. A mansão de Savoye e a Rotonda são ambas muito famosas; mas também são, em cada caso, mais obviamente platônicas e fáceis de interpretar. Provavelmente isso se dá porque ambas estão livres, isoladas ; e que, portanto, o que está concentrado em duas frentes em Garches e Malcontenta aqui está disperso em quatro, resultando em uma genialidade bem maior de efeito externo. Mas, se há uma facilidade notável e falta de tensão a ser encontrada nessas fachadas, há desenvolvimentos análogos àqueles nas outras mansões. Tais são a preocupação de Palladio, tanto na planta como na elevação, com ênfase central e a dispersão de foco deliberada de Le Corbusier. Em Poissy, possivelmente, os volumes complexos do jardim do telhado superior substituem o telhado de duas águas e a cúpula palladianos; e novamente, talvez as quatro loggias que se projetam para o exterior estejam incluídas dentro do bloco como o terraço interno que, alternadamente, na qualidade de elemento dominante do piano nobile poderia também ser considerado correspondente ao salão abobadado da Rotonda.

Mas, simbolicamente e na esfera da beleza "costumeira", as construções de Palladio e Le Corbusier fazem parte de mundos diferentes. Palladio buscou uma clareza completa da planta e uma organização de elementos convencionais das mais lúcidas baseadas na simetria como a mais memorável forma de ordem, e na matemática como aprovação suprema no universo das formas. No entender do próprio, sua obra era, essencialmente, uma adaptação, a adaptação da residência da antiguidade, tendo sempre no fundo, como exemplo, os grandes salões das termas imperiais e construções como a villa Adriana em Tivoli. Ele tinha vários esquemas da reconstrução arqueológica de residências gregas e romanas baseados em Vitrúvio e Plínio, incorporando elementos que na prática greco-romana seriam encontrados em prédios públicos, mas que ele considerava como sendo gerais. Na realidade, Roma para ele ainda estava extremamente viva; e se os antigos haviam adaptado um templo a partir de uma residência, o planejamento em larga escala refletiria, sem dúvida alguma, semelhanças. 
Notadamente, Le Corbusier tem a mesma reverência pela matemática e ele também, ao que tudo indica, às vezes, carrega marcas de um historicismo semeIhante. Para seus projetos parece que encontrava pelo menos uma fonte nos ideais da convenance (conveniência) e commodité (comodidade) exibidos no briIhante planejamento do hotel Rococo, o pano de fundo de uma vida social ao mesmo tempo mais ampliada e íntima. Os franceses, até recentemente, seguiam uma tradição ininterrupta desse tipo de planejamento; e, portanto, pode-se com frequência descobrir, em uma utilização das Belas Artes de um local irregular, elementos que se não precediam Le Corbusier poderiam dar a impressão de que, curiosamente, lembram a suavidade intensa de seus próprios vestíbulos e boudoirs. Le Corbusier admira a arte bizantina e a arquitetura anônima do mundo mediterrâneo; e há nele também a presença de um prazer puramente francês nos aspectos mais óbvios da mecânica. O pequeno pavilhão no telhado de Garches é, ao mesmo tempo, um templo ao amor e um convés de um navio. Os volumes arquitetônicos mais complexos são equipados com água corrente.

Em termos geométricos, pode-se considerar que ambos os arquitetos tenham se aproximado um tanto do arquétipo platônico da villa ideal ao qual se pode supor que a fantasia do sonho virgiliano esteja relacionada; e também se poderia supor que a realização de uma ideia representada pela casa na forma de um cubo se prestaria de pronto aos propósitos do sonho de Virgílio. Pois aqui se arma o conflito entre o absoluto e o contingente, o abstrato e o natural; e a lacuna entre o mundo ideal e as necessidades por demais humanas de realização aqui têm sua mais patética representação. O preenchimento de tal lacuna deve se dar de maneira tão competente e convincente quanto a construção de boas perspectivas fugadas; e, caso venha carregada, como em Malcontenta, de uma seriedade quase religiosa, ou, como em Garches, imbuída de alusão sofisticada e espirituosa, a organização bem sucedida é um feito intelectual que reconcilia a mente com o que podem ser discrepâncias fundamentais no programa.

Como um construtor de perspectivas arquitetônicas, Palladio é um classicista convencido pelo repertório de formas bem humanizadas do século XVI; e ele traduz esse material herdado com paixão e imensa seriedade condizentes com a validade contínua que ele acredita que tal material possui. A referência ao Panteão nos frontões sobrepostos de Malcontenta, às termas no salão cruciforme, a ambiguidade, profunda tanto 
na ideia como na forma, na conjunção inequívoca da fachada do templo com o bloco residencial; todos esses elementos são repletos de significado, tanto pelo que são como pelo que significam; e a impressão que deixam é comovente. Mas a residência antiga não é recriada por meio de tal aparato, mas algo bem mais significativo é alcançado: uma nostalgia criativa evoca a manifestação de um poder mítico através do qual se equacionam o romano e o ideal.

Em contrapartida, Le Corbusier é, de várias maneiras, o mais católico e brilhante dos ecléticos. As ordens, as referências romanas, eram a vestimenta arquitetônica tradicional da autoridade; e, se é difícil para o arquiteto moderno ser tão enfático a respeito de uma determinada civilização como foi Palladio em relação aos romanos, com Le Corbusier há sempre um elemento de sagacidade sugerindo que a referência histórica (ou contemporânea) seja mantida como uma citação entre aspas, possuindo sempre o duplo valor da citação, as associações com os contextos antigo e novo. Apesar de admirar a Acrópole e Michelangelo, o mundo da alta cultura clássica mediterrânea na qual Palladio se baseou de maneira tão expressiva está, de um modo geral, vedado a Le Corbusier. Os acessórios ornamentais de humanismo, as representações emblemáticas das virtudes morais, aos amores dos deuses e as vidas dos santos perdem o monopólio que tinham anteriormente; e, como resultado, enquanto a alusão em Malcontenta é concentrada e diireta, em Garches é dissipada e inferencial. Dentro do cubo único a performance arrisca o romano; mas, dentro do outro, um ideal cultural exclusivo de tal ordem não é cogitado. Em vez disso, como os patrocinadores de sua virtuosidade, Le Corbusier seleciona em grande parte uma variedade de fenômenos até então não discriminados. Ele seleciona incidentes ocasionais de Paris, ou Istambul, ou onde quer que ocorram; aspectos do fortuitamente pitoresco, do mecânico, de objetos considerados típicos, do que quer que possa parecer representante do presente ou do passado utilizável; e todos esses itens, embora transformados por um novo contexto, retêm as implicações originais que signifiquem talvez o ideal platônico, talvez a intimidade do rococó, talvez a precisão mecânica, talvez o processo de seleção natural. Ou seja, podemos apreender todas essas referências como algo já conhecido; mas, apesar do novo poder do qual se tornaram investidas, são apenas transitoriamente provocadoras. De maneira diferente das formas de Palladio, não há nada definitivo acerca de qualquer uma dessas possíveis relações; e suas aproximações pareceriam afetadas pelo esvaziamento artificial do cubo em que se encontram 
localizadas, quando os sentidos são confundidos pelo que é aparentemente arbitrário e o intelecto é mais do que convencido, apesar de tudo que se levante em contrário, pelo conhecimento intuitivo dos problemas aqui tenham sido apontados e resolvidos e da existência aqui de uma ordem razoável.

A villa neo-palladiana tornou-se, na melhor das hipóteses, um objeto pitoresco no parque inglês e Le Corbusier passou a ser a fonte de inúmeros pastiches de técnicas de exibição tão divertidas que chegam a ser enfadonhas; mas é a qualidade magnífica de realização dos originais que é raramente encontrada nas obras dos neo-palladianos e dos expoentes de "le style Corbu". ${ }^{17}$ Essas distinções quase nunca precisam de reforço; e, sem dúvida alguma, deve-se acatar a sugestão de que, no caso das obras derivadas, talvez o que tenha se extinguido tenha sido uma adesão a "regras".

\section{Adendo de 1973}

Embora um paralelo entre Schinkel e Corbu em sua última fase talvez não seja tão gratificante quanto a comparação da primeira fase de Corbu com Palladio, muitos dos argumentos como os que vieram à tona neste artigo possam ser desenvolvidos se, no lugar da Villa Malcontenta, se venha a considerar o Museu Altes de Berlim e, em vez de Garches, o Palácio da Assembleia de Chandigarth. As ilustrações (Figuras 14, 15 e 16) talvez fossem suficientes para se estabelecer um ponto de vista: um partido clássico convencional equipado do tradicional poché , ou seja, do tradicional bloco, e muito do mesmo partido distorcido e levado a apresentar uma variedade de gestos locais - talvez para serem entendidos como compensações pelo poché tradicional.

Uma crítica que se inicia com configurações aproximadas e que então procede a identificar diferenças, que busca estabelecer como o mesmo tema geral pode ser transformado de acordo com a lógica (ou a compulsão) de estratégias analíticas (ou estilísticas) específicas, talvez seja wolfiniana em sua origem; e suas limitações devem ser óbvias. Não pode ela, com toda a seriedade, lidar com questões de iconografia e conteúdo; talvez seja por demais simétrica; e, porque é tão dependente de uma análise minuciosa, se prolongada, inevitavelmente irá exercer uma enorme pressão tanto no consumidor como no produtor. No entanto, caso não se deseje se imaginar confrontado com os resultados de um intenso exercício crítico sobre o materiel ${ }^{18}$ fornecido pelos Museu Altes e Palácio
17 NT: no original, o autor não traduz a expressão em francês, que significa o estilo de Le Corbusier, ou estilo corbu.
18 NT: o autor não traduz para o inglês o termo em francês. 


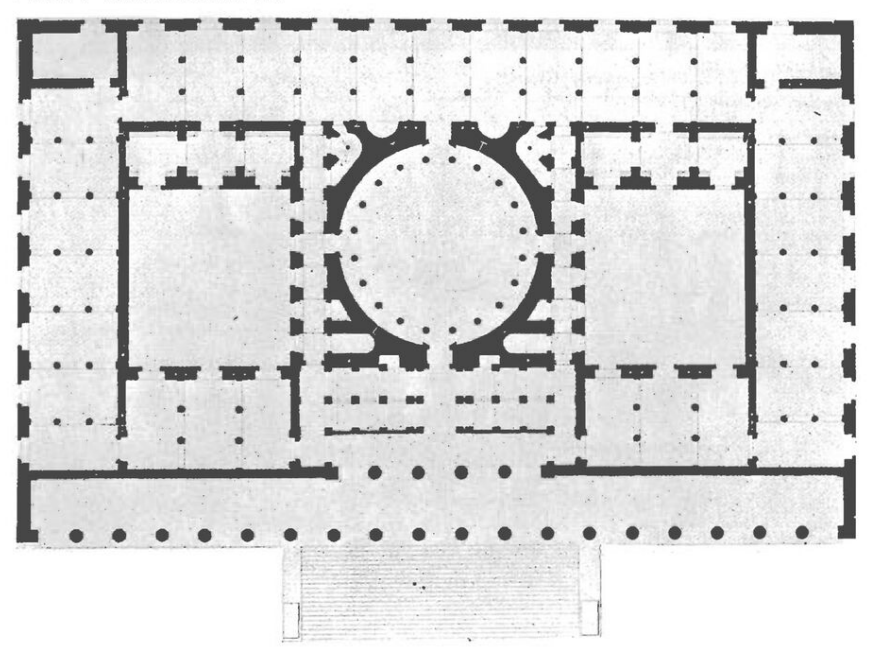

Figura 14

Altes Museum, Berlim. K. F. Schinkel, 1823

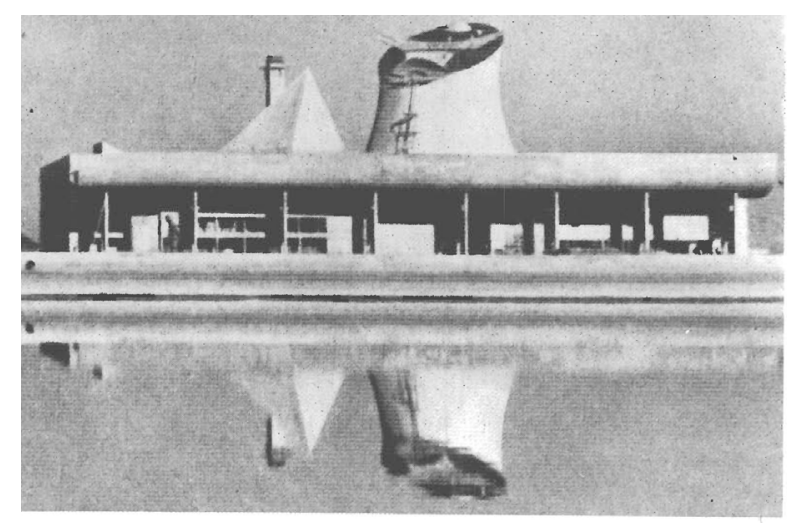

Figuras 15 e 16

Palácio da Assembléia de Chandigarh. Le Corbusier, 1953

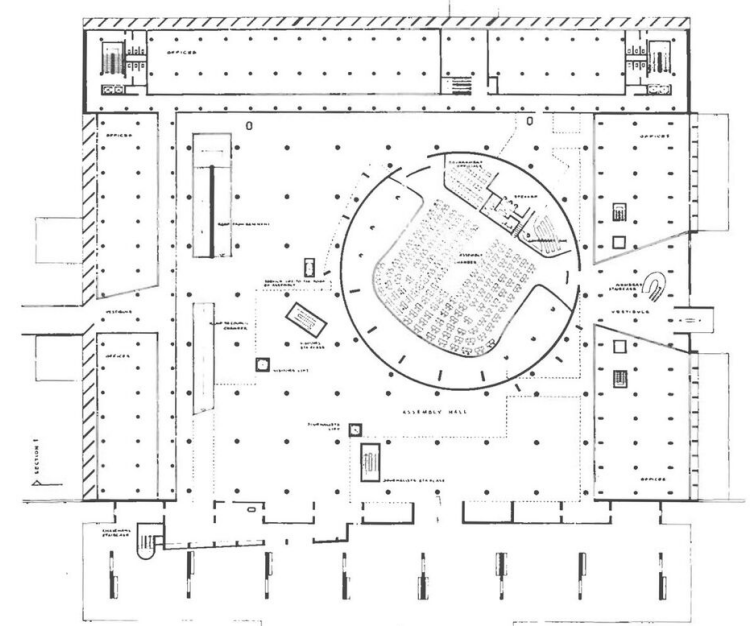

